\title{
AS CONDIÇÕES DE (IM) POSSIBILIDADE DA EXPERIÊNCIA EM JOHN DEWEY E JORGE LARROSA: ALGUMAS APROXIMAÇÕES
}

\author{
Dariane Carlesso ${ }^{1}$ \\ Elisete Medianeira Tomazetti ${ }^{2}$
}

\section{Resumo}

Este artigo tem por objetivo refletir sobre as condições para que o acontecimento ou a construção/reconstrução da experiência possam fazer parte do processo de constituição do sujeito. Duas fontes teóricas serão as principais fundamentadoras desta escrita: John Dewey e Jorge Larrosa. Estes autores apresentam contribuições singulares para o campo de problematização do conceito de experiência e, por isso, merecem nossa atenção. Dentre as teses de John Dewey (1859-1952), filósofo norte-americano que nos deixou um imenso legado filosófico educacional, encontramos a defesa de um processo educativo pautado na ideia de educação como construção e reconstrução da experiência. Jorge Larrosa é professor de Filosofia da Educação na Universidade de Barcelona, na Espanha, e autor de várias publicações sobre educação. Dentre seus trabalhos destacamos: "Notas sobre a experiência e o saber de experiência" (2002) e "Saber e Educação" (2007), aos quais nos reportamos na escrita deste artigo, dada a propriedade com que os conceitos de experiência e educação são neles abordados. A problematização deweyana sobre o conceito de experiência é amplo. Diversas são as obras que dão suporte a este tema; no entanto, citamos como principais: Experiência e educação (1971), Como pensamos: como se relaciona o pensamento reflexivo com o processo educativo (1959a), Democracia e educação (1959b), Vida e educação (1973).

Palavras-chave: Experiência; Construção, Acontecimento; Educação; Escola

\section{Considerações Iniciais}

\footnotetext{
${ }^{1}$ Dariane Carlesso. Endereço: Rua Clevelândia, 442D, Edifício Ana Laura, 204, Chapecó, SC. Tel. (49)91317927. Pedagoga, Mestre em Educação pela Universidade Federal de Santa Maria. Pedagoga da Universidade Federal da Fronteira Sul, Campus Chapecó. E-mail: darianecarlesso@gmail.com.

${ }^{2}$ Elisete Medianeira Tomazetti. Endereço: Rua Carlos Uhr, 31/201, Santa Maria, RS. Tel. (55)99788552. Professora do Departamento de Metodologia do Ensino e do Programa de Pós-Graduação da Universidade Federal de Santa Maria. E-mail: elisetem2@ gmail.com.
} 
Este artigo tem por objetivo a reflexão sobre as condições para que o acontecimento ou a construção/reconstrução da experiência façam parte do processo de constituição do sujeito. Duas fontes teóricas serão as principais fundamentadoras desta escrita: John Dewey e Jorge Larrosa. Estes autores apresentam contribuições singulares para o campo de problematização do conceito de experiência e, por isso, merecem nossa atenção.

Dentre as teses de John Dewey (1859-1952), filósofo norte-americano que nos deixou um imenso legado filosófico educacional, encontramos a defesa de um processo educativo pautado na ideia de educação como construção e reconstrução da experiência, a qual foi amplamente estudada no período de construção da dissertação de mestrado que é referência deste texto ${ }^{3}$. A problematização deweyana sobre o conceito de experiência é amplo. Diversas são as obras que dão suporte a este tema; no entanto, citamos como principais: Experiência e educação (1971), Como pensamos: como se relaciona o pensamento reflexivo com o processo educativo (1959a), Democracia e educação (1959b), Vida e educação (1973).

Jorge Larrosa é professor de Filosofia da Educação na Universidade de Barcelona, na Espanha, e autor de várias publicações sobre educação. Dentre seus trabalhos destacamos: "Notas sobre a experiência e o saber de experiência" (2002) e "Saber e Educação" (2007), aos quais nos reportamos na escrita deste artigo, dada a propriedade com que os conceitos de experiência e educação são neles abordados.

O presente texto transitará pelo conceito de experiência presente nas obras de Jorge Larrosa e John Dewey. Com Larrosa, o exercício inicial será compreender aquilo que denominamos cotidianamente como experiência e, neste caminho, nos aproximarmos da obra deweyana, especificamente dos argumentos e princípios que sustentam o conceito de experiência. De cada um dos autores, serão destacados os argumentos acerca da experiência, assim como as situações por eles consideradas impossibilitadoras da experiência.

A partir das características atribuídas pelos autores à experiência, faremos o exercício de confluência das ideias de ambos. Apontar as possíveis ligações entre Dewey e Larrosa será, portanto, um dos desafios deste texto. Este diálogo poderá

\footnotetext{
${ }^{3}$ Dissertação intitulada John Dewey e a educação como "reconstrução da experiência": um possível diálogo com a educação contemporânea, defendida no ano de 2008 pelo Programa de Pós-Graduação em Educação, da Universidade Federal de Santa Maria, RS.
} 
revelar não só a atualidade da obra de Dewey, como também as riquezas e potencialidades presentes na exploração do conceito de experiência para a educação contemporânea.

Todavia, realizar o diálogo entre autores de tempos históricos tão diferentes exige não apenas do escritor, mas também do leitor a compreensão das singularidades que envolvem os tempos e as condições em que foi escrita cada uma das obras aqui referenciadas. Este exercício será profícuo na medida em que conseguirmos focalizar a importante dimensão que tem a experiência nas atividades educativas e, portanto, nas atividades de constituição do sujeito.

\title{
2. As possibilidades e impossibilidades da experiência a partir de John Dewey e Jorge Larrosa
}

\begin{abstract}
A experiência vem sendo concebida, desde a modernidade, como a relação do sujeito com o mundo e consigo mesmo, por meio da qual aquele começa a conhecer a este pelos órgãos dos sentidos e, paulatinamente, a reconhecer-se conscientemente, em suas ações pelo juízo reflexivo, em vista da aquisição de saberes capazes de auxiliá-lo na condução de sua vida. Nesses termos, a experiência tem sido concebida como desencadeadora do processo do conhecimento, no qual se fundamentam as práticas e os saberes escolares, constituindo um conceito-chave da filosofia da educação, embora bastante controvertido, no âmbito de suas tradições. (PAGNI, 2010, p. 15)
\end{abstract}

John Dewey e Jorge Larrosa argumentam a favor do papel "formador" da experiência; ambos defendem o experienciar como parte constituidora do sujeito. Em Dewey (1973), por exemplo, encontra-se a ideia de educação como construção e reconstrução da experiência, já em Larrosa, a ideia de acontecimento da experiência. No entanto, a experiência envolve fatores que, segundo os autores, não podem ser reduzidos ao simples "fazer". Experienciar, para eles, é viver determinadas condições que dão possibilidade para que a experiência se efetive. Será investigando e pontuando estas condições "propícias" para a experiência que buscaremos elementos de confluência entre os pensadores.

Considerando a premissa de que as experiências são constituidoras dos sujeitos que as vivem, fica clara a ligação entre a experiência e os fatores que a possibilitam ou não na sociedade e nas instituições educacionais. Este pressuposto inicial nos ajuda a entender a crítica que Dewey faz à escola tradicional, por esta não oportunizar ao aluno a construção e reconstrução de experiências. Da mesma maneira, podemos entender a 
leitura que Larrosa faz da sociedade atual, da vida do sujeito moderno, o qual não encontra no seu cotidiano condições para que a experiência aconteça.

Para os autores, existem situações mínimas que se revelam como condições indispensáveis para que o sujeito viva experiências e, desta forma, tenha nelas fonte de formação contínua. A fim de compreender os elementos caracterizadores da experiência, apresentamos as palavras de Jorge Larrosa:

[...] poderíamos dizer, de início, que a experiência é, em espanhol, "o que nos passa" em português se diria que a experiência é "o que nos acontece"; em francês a experiência seria "ce que nous arrive", em italiano, "quello che nos succede" ou "quello che nos accade" em inglês, "That what is happening to us"; em alemão, "Was mir passiert". (LARROSA, 2003, p. 21)

Entende-se, pelas definições acima, que a experiência não se basta como algo exterior ao sujeito, mas sinaliza uma interface entre interior e exterior; logo, o sujeito que a vive, nos sentidos mencionados acima, permite que algo lhe aconteça, que algo lhe toque, que algo lhe suceda. O sujeito da experiência é consciente de sua condição de construtor do seu conhecimento, de sua personalidade e de sua formação.

Esta ideia - do protagonismo do sujeito, a que se refere Larrosa - aproxima-se da expressa na obra deweyana. Como sabemos, para Dewey, a centralidade do processo educacional está no aluno; por conseguinte, o conceito de educação como construção e reconstrução da experiência não se limita ao que é externo ao sujeito. Existe um elemento central que leva cada sujeito a protagonizar seu processo de construção de experiência, que é a reflexão:

O termo experiência pode interpretar-se seja como referência à atitude empírica, seja como referência à atitude experimental. A experiência não é coisa rígida e fechada; é viva e, portanto, cresce. Quando dominada pelo passado, pelo costume, pela rotina, opõe-se, frequentemente, ao que é razoável, ao que é pensado. A experiência inclui, porém, ainda a reflexão, que nos liberta da influência cerceante dos sentidos, dos apetites da tradição. Assim, torna-se capaz de acolher e assimilar tudo o que o pensamento mais exato e penetrante descobre. De fato, a tarefa da educação poderia ser definida como emancipação e alargamento da experiência. (DEWEY, 1959a, p. 199)

O sujeito da experiência para Dewey é aquele que exerce o pensamento reflexivo, que é capaz de voltar-se para si e assimilar aquilo que se lhe apresenta de novo, em um movimento de contínua construção e reconstrução de experiências. Este pressuposto está tão presente nos escritos deweyanos que a tarefa da educação, para ele, está na busca pela emancipação e pelo alargamento da experiência. 


\subsection{Elementos impossibilitadores da experiência}

Para Dewey e Larrosa, há alguns elementos que são considerados inimigos da experiência. No texto de Jorge Larrosa (2002), a crítica volta-se para as condições de vida do sujeito moderno, o qual está desassistido de possibilidades de experiência, dado seu estilo de vida. Já para Dewey, a escola tradicional trabalhou moldes de educação que inviabilizaram qualquer atividade de experiência na escola, por seu caráter conteudista e livresco, distante da vida dos alunos.

Conforme as argumentações trazidas por Jorge Larrosa em seu texto "Notas sobre a experiência e o saber de experiência" (2002), existem situações às quais o sujeito contemporâneo está exposto e que são incapazes de oportunizar o acontecimento da experiência - uma delas é o excesso de informação. Nos tempos atuais, muitas coisas se passam ao nosso redor, uma multiplicidade de situações acontecem em concomitância; no entanto, pouco de tudo isso nos passa, pouco nos acontece: "A cada dia se passam muitas coisas, porém, ao mesmo tempo, quase nada nos acontece [...] uma sociedade constituída sob o signo da informação é uma sociedade na qual a experiência é impossível" (LARROSA, p. 21-22). Assim, em contrapartida ao excesso de informações, o sujeito contemporâneo tem suas possibilidades de experiência limitadas, pois o saber da experiência é diferente da aquisição de informações sobre as coisas. A informação não exige do sujeito a complexidade de significações que a experiência exige; logo, nada lhe passa. Ao sujeito que vive a experiência, algo lhe acontece, ele não se informa simplesmente.

Nas palavras de Dewey, este elemento - "informação" - pode ser traduzido para "as coisas com que nos ocupamos". A experiência perde seu potencial na medida em que o sujeito torna-se incapaz de realizar as possíveis conexões entre as coisas com que se ocupa:

Acostumamo-nos tão completamente a uma espécie de pseudo-ideia, de meia percepção, que não temos acordo de quanto é semimorta a nossa atividade mental e quanto mais penetrantes e extensas seriam nossas observações e ideias, se as formássemos em meio às condições de uma experiência vivificante que requeresse, de nossa parte, o esforço de pensar e o uso do raciocínio: fazendo-nos procurar as conexões das coisas com que nos ocupamos. (DEWEY, 1959b, p. 157) 
As condições de construção de uma "experiência vivificante", como sinaliza Dewey, são impossibilitadas na medida em que se valorizam excessivamente "as coisas" em detrimento do esforço de pensar e de conectar situações.

Para Larrosa, outro fator limitador da experiência é a necessidade de opinar sobre as informações. Este imperativo leva o sujeito a pautar-se na informação pela necessidade de opinião. Molda-se a personalidade de "um sujeito fabricado e manipulado pelos aparatos da informação e da opinião, um sujeito incapaz de experiência" (2002, p. 22). O excesso de opinião, o periodismo, como denomina Larrosa, faz com que o sujeito moderno opine quase que como reflexo das informações que recebe constantemente.

Situação similar é descrita na obra de Dewey, na medida em que ele trata o pensamento reflexivo como parte da construção da experiência. Logo, toda a atividade que se restringir a reflexos, a impulsos ou desejos é uma atividade que, por si só, não alcança a construção e reconstrução de experiências:

[...] não há crescimento intelectual sem reconstrução, sem que, de algum modo, a forma em que se manifestam de início estes desejos e impulsos seja revista e refeita [...] pensar é, assim, livrar-se da ação imediata, enquanto a reflexão, pela observação e pela memória, efetua o domínio interno do impulso. (DEWEY, 1971, p. 63)

Para Dewey (1959a, p. 105-106), “a função do pensamento reflexivo é, por conseguinte, transformar uma situação de obscuridade, dúvida, conflito, distúrbio de algum gênero, numa situação clara, coerente, assentada e harmoniosa". A necessidade de reflexão diante dos impulsos e desejos pressupõe a possibilidade de dar continuidade às experiências que construímos. Sem um encadeamento de ideias, sem uma sequência minimamente organizada dos acontecimentos que compõem a ação, agir-se-ia como "se escrevêssemos na água" (DEWEY, 1959b, p. 153).

No caso do sujeito moderno, a falta de tempo e as ações de opinar são tão imediatas que o "estímulo fugaz e instantâneo é imediatamente substituído por outro estímulo ou por outra excitação igualmente fugaz e efêmera" (LARROSA, 2002, p. 23). Neste caminho de vivências instantâneas, pontuais e fragmentadas, a experiência não acontece: a "conexão significativa entre os acontecimentos" (2002, p. 23) é impedida pela velocidade e o que ela provoca.

Essa conexão a que se refere Larrosa está descrita com cuidado na obra de Dewey, tanto que o continuum é um princípio para a experiência deweyana e sua 
ausência faz com que esta última perca seu sentido: "o princípio de continuidade de experiência significa que toda e qualquer experiência toma algo das experiências passadas e modifica de algum modo as experiências subsequentes" (DEWEY, 1971, p. 26).

Cabe ao educador, portanto, dispor "cousas para as experiências" e oportunizar que estas não sejam "apenas imediatamente agradáveis", mas que enriqueçam o aluno e, sobretudo, armem-no para novas experiências futuras - princípio de continuidade (DEWEY, 1971). Nesse processo, em que há uma comunidade de pensamento, ao aluno não só é oferecido o que é novo, como também lhe são criadas condições de agregar o desconhecido ao já conhecido, desafiando-o a aventurar-se na construção do novo conhecimento e nas potencialidades de experiência que dali advêm. Desta maneira, descartar o continuum fere diretamente a compreensão de educação como construção e reconstrução da experiência defendida por Dewey.

Com relação à falta de tempo para permitir-se o acontecimento da experiência, Larrosa ainda pontua que são inimigos dela também a falta de silêncio e de memória. Em vista deste ambiente acelerado, o autor afirma:

Estou cada vez mais convencido de que os aparatos educacionais também funcionam cada vez mais no sentido de tornar impossível que alguma coisa nos aconteça [...] na escola o currículo se organiza em pacotes cada vez mais numerosos e cada vez mais curtos. Com isso, também em educação estamos sempre acelerados e nada nos acontece. (LARROSA, 2002, p. 23)

Para Dewey, o pensamento reflexivo, elemento fundante da experiência, também exige conexão com o silêncio e com a memória.

[...] o problema de método na formação de hábitos de pensamento reflexivo é o problema de estabelecer condições que despertem e guiem a curiosidade; de preparar, nas coisas experimentadas, as conexões que, ulteriormente, promovam o fluxo de sugestões, criem problemas e propósitos que forneçam a consecutividade na sucessão de ideias. (DEWEY, 1959a, p. 63)

As formas como se constituem os currículos escolares são determinantes para que haja ou não a construção ou acontecimento da experiência. Tanto em Larrosa, quanto em Dewey está implícita a compreensão de que nos ambientes escolares moldam-se formas de pensar, tanto que tal instituição torna-se responsável por modular hábitos do exercício do pensar (VALDEMARIN, 2005), os quais nem sempre geram condições para que a experiência ocorra. 
$\mathrm{O}$ processo educativo, segundo Dewey, tende a reduzir a aprendizagem à absorção direta de conhecimentos, privando o aluno de "passar por experiências frutíferas”. O sistema tradicional de educação, para Dewey, além de não primar pelo encadeamento necessário entre presente, passado e futuro, torna dicotômica a relação corpo e mente, que, para agravar ainda mais seus déficits, vem sendo unilateral: "se estão formando atitudes e hábitos que impedirão aprendizagens futuras, que resultam do fácil e pronto contato e comunicação com os outros” (DEWEY, 1971, p. 57).

Para Larrosa, outro fator inviabilizador da experiência é o excesso de trabalho:

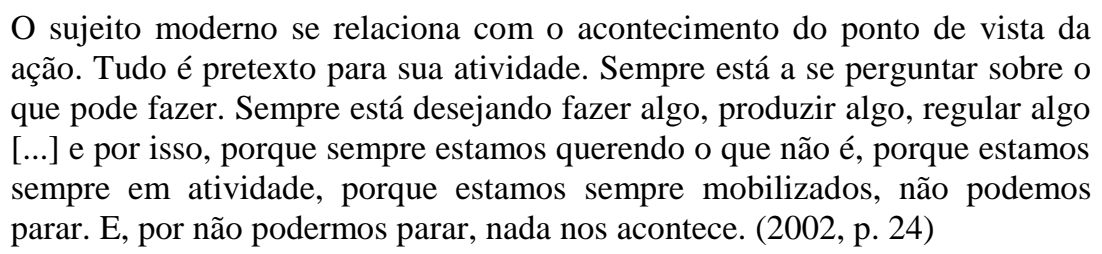

A aceleração a que se refere Larrosa leva o sujeito moderno à multiplicidade de ações que levam à hiperatividade. Não há tempo para parar, apenas para realizar atividades e permanecer naquilo que se convencionou como "útil"; é suprimida toda e qualquer possibilidade de que algo aconteça e gere o que o autor denomina como experiência.

Também para John Dewey, "a simples atividade não constitui experiência" (1959b); a experiência vai além, é mais complexa. Logo, o que caracteriza a atividade não dá conta da amplitude de uma experiência. A primeira é dispersiva, centrífuga e dissipadora, ou seja, não necessita de um eixo ou uma linha condutora que possibilite a relação consciente entre as consequências por ela geradas. Diferentemente, a segunda, a experiência, caracteriza-se por um fluxo e refluxo alimentados de significação. E esta significação só acontece quando há uma continuidade na atividade, gerando mudança naquele que pratica a ação, conforme afirma Dewey.

Nesse sentido, o autor explica que "Não existe experiência quando uma criança simplesmente põe a mão no fogo, será experiência quando o movimento se associa com a dor que ela sofre, em consequência daquele ato" (DEWEY, 1959b, p. 152). A atividade, se não percebida como resultado de outra ação, assim adquirindo significação junto ao sujeito que a pratica, não pode ser denominada como experiência: "Sem algum elemento intelectual não é possível nenhuma experiência educativa” (p. 158). 


\title{
2.2 Elementos possibilitadores da experiência
}

Os elementos possibilitadores da experiência, tanto para Dewey quanto para Larrosa, incluem situações nas quais o sujeito passa a ser autor do processo de conhecer. Estes elementos vêm sendo sinalizados desde o início deste texto, até mesmo ao pontuarmos aquilo que inibe a experiência, pois, na medida em que somos capazes de definir os empecilhos da construção ou do acontecimento da experiência, estamos indiretamente afirmando as condições ideais para que esta se efetive.

O movimento de experienciar, seja ele protagonizado pelo aluno em sala de aula, seja pelo sujeito moderno em seu cotidiano, é permeado por situações propícias, que levam o sujeito/aluno a uma ampliação significativa das experiências já vivenciadas. Para Larrosa:

\begin{abstract}
A experiência, a possibilidade de que algo nos aconteça ou nos toque, requer um gesto de interrupção, um gesto que é quase impossível nos tempos que correm: requer parar para pensar, parar para olhar, parar para escutar, pensar mais devagar, olhar mais devagar, e escutar mais devagar; parar para sentir, sentir mais devagar, demorar-se nos detalhes, suspender a opinião, suspender o juízo, suspender a vontade, suspender o automatismo da ação, cultivar a atenção e a delicadeza, abrir os olhos e os ouvidos, falar sobre o que nos acontece, aprender a lentidão, escutar aos outros, cultivar a arte do encontro, calar muito, ter paciência e dar-se tempo e espaço. (2002, p. 24)
\end{abstract}

Estes elementos, para Larrosa, são fundamentais para que o sujeito torne-se capaz de experienciar. Notamos que isso não é simples e que o sujeito é o principal responsável por buscar criar condições de possibilidade para que algo lhe aconteça. Um elemento que aparece com frequência no texto deste autor é a necessidade de "parar". O sujeito da experiência em Larrosa é aquele que tem a capacidade de olhar para seu tempo com paciência, com lentidão, com demora nos detalhes, num gesto de interrupção.

Delineiam-se aqui algumas das condições de possibilidade da experiência que são fundamentais para Larrosa e que também aparecem na obra de Dewey como contraponto ao excesso de atividade, a qual é confundida muitas vezes com experiência:

Pode-se gastar muito tempo acreditando que ser uma pessoa em atividade é o suficiente para garantir experiência. Isso não é verdade. Para Dewey, a experiência é mais complexa do que tal definição, tanto que ela envolve não somente a dimensão ativa do acontecimento, mas também a dimensão passiva e a consciência de continuidade por parte do agente. (CARLESSO, 2008, p. 74) 
Se para Larrosa o sujeito precisa "parar" para construir a experiência, para Dewey o sujeito precisa incorporar elementos que vão além da sobreposição de atividades e incluir em sua vida o exercício que leva a "aprender como pensar bem, especialmente como adquirir o hábito geral de refletir" (DEWEY, 1959a, p. 42). O pensamento reflexivo é elemento vital da experiência e ele só se constitui na medida em que o sujeito aprende a exercitar e dar o tempo suficiente para esta construção, encadeando o que Dewey denomina como dimensão ativa e dimensão passiva da experiência. Nos termos deweyanos, o sujeito da experiência é aquele que se torna capaz de aprender da experiência:

\begin{abstract}
'Aprender da experiência' é fazer uma associação retrospectiva e prospectiva entre aquilo que fazemos às coisas e àquilo que em consequiência essas coisas nos fazem gozar ou sofrer. Em tais condições a ação torna-se uma tentativa; experimenta-se o mundo para se saber como ele é; o que se sofrer em consequência torna-se instrução - isto é, a descoberta das relações entre as coisas. (DEWEY, 1959b, p. 153)
\end{abstract}

Larrosa acredita igualmente que as condições de possibilidade para o acontecimento da experiência exigem do sujeito uma postura própria:

O sujeito da experiência seria algo como um território de passagem, algo como uma superfície sensível que aquilo que acontece afeta de algum modo, produz alguns afetos, inscreve algumas marcas, deixa alguns vestígios, alguns efeitos [...]. O sujeito da experiência é sobretudo um espaço onde têm lugar os acontecimentos. (LARROSA, 2002, p. 24)

Este ponto exprime outra possível confluência entre os autores aqui estudados e merece nossa especial atenção, pois trata do sujeito da experiência, aquele que para Larrosa é o "território de passagem" e que para Dewey é o capaz de "gozar ou sofrer". Nas duas situações identificamos um sujeito que vive a experiência e está permeado por um elemento passivo. Logo, não é aquele que simplesmente executa a ação, que se informa e opina, que age por impulsos e desejos ou que participa de inúmeras atividades, mas é aquele que admite sua receptividade diante da experiência que vivencia.

Em seu aspecto ativo, a experiência é tentativa - significação que se torna manifesta nos termos experimento, experimentação que lhe são associados. No aspecto passivo ela é sofrimento, passar por alguma coisa. Quando experimentamos alguma coisa, agimos sobre ela, fazemos uma coisa com ela; em seguida, sofremos ou sentimos as consequências. (DEWEY, 1959b, p. 152) 
Esta passividade que encontramos nos dois autores é caracterizadora da compreensão de experiência como situação constituidora do sujeito. O sujeito passional (não apenas ativo e nem simplesmente passivo) sofre ou sente as consequências daquilo que se permitiu vivenciar. Na experiência, o sujeito é receptivo àquilo que é "novo", ao acontecimento da experiência, nos termos de Larrosa, ou à construção e reconstrução da mesma, segundo Dewey.

Se, para Larrosa, a crítica maior está no estilo de vida do sujeito do mundo moderno, o qual, por carência de experiências, não permite que as coisas do seu tempo lhe passem, façam parte de sua vida significativamente, para Dewey, a educação de sua época estava descontextualizada e, por não promover a construção e reconstrução de experiências, não se voltava para a vida dos que dela participavam: "Creo que toda educación procede de la participación del individuo en la consciencia social de la raza [...] un proceso de vida y no de una preparación para la vida que vendrá.” (DEWEY, 2003, p. 92). A promessa de utilização futura dos conhecimentos escolares, bem como a fragmentação dos saberes, inviabilizou e ainda inviabiliza muitas dinâmicas de ensino e de aprendizagem: "Aprender? Certamente, mas antes de mais viver, e aprender através e em interação com esta vivência" (DEWEY, 2002, p. 40-41).

Também para Larrosa, a verdadeira sabedoria e aprendizagem somente podem "redimirse si son, de algún modo apropriadas, interiorizadas, em la propia sustancia del alma. Es el hombre el que tiene que dar vida y realidad, desde su interioridad misma, a la sabiduría" (1997, p. 40). Entretanto, as condições para que haja apropriação do conhecimento exigem do sujeito da experiência a construção de conexões entre seus saberes já constituídos, suas experiências e sua realidade.

A partir do que foi exposto, podem-se perceber aspectos do acontecimento ou da (re)construção da experiência que marcam a particularidade da escrita de cada autor, mas que, mesmo assim, repercutem em uma aproximação de conceitos. Para Larrosa, o sujeito da experiência é, antes de ativo ou passivo a uma experiência, aquele que se expõe - "se expõe atravessando um espaço indeterminado e perigoso, pondo-se nele à prova e buscando nele sua oportunidade, sua ocasião" (2002, p.25) - e tem como receptividade primeira uma passividade feita de paixão, de padecimento, de paciência, de atenção, pressupondo assim uma abertura essencial àquilo que lhe passa. Para Dewey, a experiência pode ter caráter positivo ou negativo; logo, ela pode resultar em situações que impeçam a progressão na construção do conhecimento sobre determinado 
assunto, bem como fomentar o contínuo aperfeiçoamento do conhecimento sobre um outro: "Uma experiência pode ser tal que produza dureza, insensibilidade, incapacidade de responder aos apelos da vida, restringindo, portanto, a possibilidade de futuras experiências mais ricas" (DEWEY, 1971, p. 14). Para Larrosa (2002, p. 25), a experiência pressupõe uma condição de abertura, de exposição "com tudo o que isso tem de vulnerabilidade e risco". Sob este ponto de vista, o risco é de que as marcas não sejam necessariamente as melhores, uma condição que se assemelha àquilo que Dewey denomina como possibilidade de experiências negativas. Assim, o sujeito que se expõe, para Larrosa, é também o sujeito que está à mercê de experiências positivas ou negativas, segundo Dewey.

Esta condição, própria de quem experimenta, pressupõe ainda que o sujeito que vive experiências não se apodera apenas daquilo que quer, ele permite-se alcançar por completo, é "um sujeito sofredor, padecente, receptivo, aceitante, interpelado, submetido" (LARROSA, 2002, p. 25). A capacidade de formação e transformação é componente fundamental da experiência para Jorge Larrosa: "Somente o sujeito da experiência está, portanto, aberto à sua própria transformação" (2002, p. 26). É esta transformação que, em termos deweyanos, diz respeito ao processo de construção $e$ reconstrução de experiências, o qual, como que em um movimento espiral, motiva a transformar, pelo pensamento, "a matéria desconhecida em possessão familiar a instituir-se em recursos para julgar e assimilar outra matéria desconhecida" (DEWEY, 1959a, p. 286). Neste sentido, cabe a pergunta:

\footnotetext{
Que vale uma experiência que não deixe, atrás de si, uma significação ampliada, uma melhor compreensão de alguma coisa, um plano e um propósito mais claro de ação futura, em suma, uma ideia? Com respeito ao ensino, não existe ponto mais importante do que a questão da maneira pela qual genuínos conceitos são formados. (DEWEY, 1959a, p. 156)
}

Entendida como uma construção, a experiência, nas palavras de Dewey, é gerida pela noção de movimento, de processo encadeado. A experiência não se resume à realização de necessidades momentâneas, irreflexivamente concebidas. A natureza da experiência provém da reflexão diante da ação possível de se realizar. Segundo Dewey, a experiência é uma ação em potencial reflexivamente praticada e gerida pelo sujeito da ação. E essa experiência se denomina enquanto tal na medida em que o sujeito percebese na condição de parar momentaneamente a atividade corriqueira e pensar suas 
diferentes possibilidades e consequências. A sequência de experiências, o contínuo reconstruir, diz do potencial de "força em marcha" a que se refere Dewey:

Se uma experiência desperta curiosidade, fortalece a iniciativa e suscita desejos e propósitos suficientemente intensos para conduzir uma pessoa aonde for preciso no futuro, a continuidade funciona como um bem diverso. Cada experiência é uma força em marcha. Seu valor não pode ser julgado se não na base de para que e para onde se move ela. (DEWEY, 1971, p. 29)

Nesta perspectiva, a situação de experiência, tanto em Dewey quanto em Larrosa, pressupõe a abertura do sujeito para aquilo que lhe é novo. Em Dewey, esta questão se apresenta na medida em que aquilo que se mostra como "novo" tenha a mínima relação com a vida do aluno, pois será isso que despertará a curiosidade, a iniciativa e as condições sob as quais o sujeito será tocado, sensibilizado. Para Larrosa, esta condição de abertura para a experiência também é imprescindível e, neste caso, é visualizada na medida em que o sujeito para e se permite experienciar, vagarosamente, a vida.

\section{3. À Guisa de Conclusão}

A atividade de experienciar está diretamente ligada com a vida. Tanto para Dewey quanto para Larrosa, o movimento da experiência coloca o sujeito como centro do processo de construção de si mesmo e do conhecimento. Enquanto para Larrosa o grande responsável por construir condições possibilitadoras de experiência é o próprio sujeito, parando, informando-se menos, opinando menos, trabalhando menos, dando-se mais tempo, para Dewey a responsabilidade por constituir condições de experiência está na escola, no currículo, no ambiente escolar e no professor. No entanto, é preciso atentar para o que afirma Marcus Vinícius Cunha (2010, p. 232): "Sugiro, pois, retomarmos a teoria deweyana, lembrando que Dewey elaborou sua pedagogia à luz dos problemas práticos que a recobrem, e que tais problemas não são exclusivamente escolares, mas também, e fundamentalmente, sociais". A sociedade de seu tempo impediria a realização de sua pedagogia, pois estaria sustentada em dicotomias como "mente versus corpo, pensamento versus ação, educação intelectual versus educação para o trabalho". (2010, p. 232). 
Cabe ressaltar que, embora se tenha interpretado a importância da experiência em Dewey como elemento fundamental para a construção/aquisição de conhecimentos, o que o afastaria, em alguns momentos, da compreensão de experiência de Larrosa, há hoje reinterpretações do conceito deweyano de experiência e de seu pragmatismo. Conforme Pedro Pagni (2010, p. 20),

Estudiosos como Jim Garrison (1999) e David Hansen (2005; 2008), reinterpretam o pragmatismo de Dewey, para elaborar uma visão holística que compreende os saberes e as práticas escolares sob seus aspectos morais, intelectuais e artísticos, conferindo unidade à práxis educativa, com base nas qualidades estéticas da experiência e em um pensamento reflexivo sustentado no instrumentalismo filosófico.

Reitera-se, então, a ideia que permeou a escrita deste texto, pois o movimento de valorização do acontecimento ou construção e reconstrução da experiência depende da atitude de delinear, minimamente, as condições de possibilidade para tal. Desta maneira, as condições previstas por Dewey e por Larrosa têm elementos comuns e, ao mesmo tempo, resgatam algo que tendemos a "esquecer" em nossa trajetória, seja na escola, seja fora dela, que é a capacidade de vivenciar situações de maneira significativa, sem atropelos e com consciência de que a formação humana exige-nos muito mais do que assistirmos as coisas passarem a partir de uma leitura simplista e acelerada da vida.

A vida, elemento fundante das situações de experiência, poderia ser reconhecida pela escola como desencadeadora de formas de pensar, de maneiras de entender e de lidar com o saber e com o cotidiano. É sob este aspecto que a teoria deweyana ganha mais força, dado que Dewey foi defensor de uma escola organizada para oportunizar "experiências vivificantes". Entretanto, nota-se que este desafio ainda permanece, pois a escola carece de situações de experiência, os mecanismos que a impossibilitam ainda resistem e, como se não bastasse, o estilo de vida do homem contemporâneo, como bem descreveu Larrosa, também reforça a lógica da "antiexperiência". O movimento de valorização da experiência no âmbito do pensamento pedagógico, que é retomado e popularizado por John Dewey ${ }^{4}$ no final do século XIX e início do século XX, e ainda hoje está presente em autores como Jorge Larrosa, sinaliza que, seja na construção $e$

\footnotetext{
${ }^{4}$ Segundo Pedro Pagni (2010, p. 15-16), a valorização da experiência como modo de conhecer o mundo e a si mesmo inicia-se com "Jean-Jacques Rousseau, a pedagogia de Wilhelm Dilthey e a filosofia da educação de John Dewey. [...] A sua gênese e desenvolvimento resultaram, didaticamente falando, em pedagogias que centraram a práxis educativa na consciência moral, na formação da consciência histórica e no pensar reflexivo, elegendo a experiência como um conceito fundamental para a atividade formativa e, por sua vez, a infância como sujeito dileto da arte pedagógica".
} 
reconstrução, seja no acontecimento, a experiência precisa ser melhor explorada, e seu potencial como situação formadora do ser humano merece nossa atenção.

\title{
CONDITIONS OF (IM)POSSIBILITY OF EXPERIENCE IN JOHN DEWEY AND JORGE LARROSA: SOME APPROACHES
}

\begin{abstract}
This essay aims at reflecting on some conditions in order for the event or the construction/reconstruction of experience may be part of the process of subject constitution. Two major theoretical foundations underscore the present approach: John Dewey and Jorge Larrosa. Such authors have great importance for the field in terms of questioning the concept of experience and, therefore, they needed our attention. Among the theories of John Dewey (1859-1952), an American philosopher who left a huge legacy in Educational Philosophy, we find the defense of an educational process based on the idea of education as construction and reconstruction of experience. Jorge Larrosa is a Professor of Philosophy of Education at the University of Barcelona, Spain, and author of various works on education. Among his publications, we can highlight the following: "Notes on the Experience and Knowledge of Experience" (2002) and "Knowledge and Education" (2007), which were referred in this paper due to the property the concepts of experience and education are used. The Deweyan problematization on the concept of experience is wide. Many works support this theme; however, only some of them are cited here as the main ones: Experiência e educação [Experience and Education] (1971), Como pensamos: como se relaciona o pensamento reflexivo com o processo educativo [How We Think] (1959a), Democracia e educação [Democracy and Education] (1959b), and Vida e educação [Life and Education] (1973).
\end{abstract}

Keywords: Experience; Construction; Event; Education; School.

\section{Referências}


CARLESSO, Dariane. John Dewey e a educação como "reconstrução da experiência": um possível diálogo com a educação contemporânea. (Dissertação de Mestrado) - Universidade Federal de Santa Maria, 2008.

CUNHA, Marcus Vinícius da. Experiência, poética e utopia na educação. In: PAGNI, Pedro; GELAMO, Rodrigo Pelloso (Org.). Experiência, educação e contemporaneidade. Marília: Poiesis, Oficina Universitária; São Paulo: Cultura Acadêmica, 2010. p. 229-235.

DEWEY, John. Pedagogos e pedagogías. Revista Educación Hoy - Revista de la confederación Católica, CIEC, Bogotá, D. C. Colombia, s/n, p. 91-102, 2003. Tradução: Luís Ernesto Solano Gutiérrez. [Texto deweyano originalmente publicado em 1897, Nova York, por Kellogg \& Co].

A escola e a sociedade e a criança e o currículo. Tradução: Paulo Faria, Maria João Alvarez e Isabel Sá. Lisboa: Relógio D’Água, 2002. [Livro originalmente publicado em 1900].

Como pensamos: como se relaciona o pensamento reflexivo com o processo educativo (uma reexposição). 3. ed. Tradução: Haydée de Camargo Campos. São Paulo: Nacional, 1959a. [Texto originalmente publicado em 1910].

Democracia e educação. 3. ed. Tradução: Godofredo Rangel e Anísio Teixeira. São Paulo: Nacional, 1959b. [Texto originalmente publicado em 1916].

Vida e educação. 8. ed. Tradução: Anísio Teixeira. São Paulo: Melhoramentos, 1973. [Comporta os textos do livro: A escola e a sociedade e a criança e o currículo (1900). Publicado no Brasil em 1973, com parte introdutória escrita por Anísio Teixeira].

Experiência e educação. Tradução: Anísio Teixeira. São Paulo: Nacional, 1971. [Texto originalmente publicado em 1938].

LARROSA, Jorge. Saber y Educación. Revista Educação e Realidade, Porto Alegre, RS, UFRGS, v. 22, n. 1, p. 33-55, 1997.

Dar a palavra: notas para uma dialógica da transmissão. In: LARROSA, Jorge; SCLIAR, Carlos (Org.). Habitantes de Babel: políticas e poéticas da diferença. Belo Horizonte: Autêntica, 2001.

Notas sobre a experiência e o saber de experiência. Revista Brasileira de Educação, n. 19, Jan./Fev./Mar./Abr. 2002.

PAGNI, Pedro. Um lugar para a experiência e suas linguagens entre os saberes e práticas escolares: pensar a infância e o acontecimento na práxis educativa. In: PAGNI, Pedro; GELAMO, Rodrigo Pelloso (Org.). Experiência, educação e contemporaneidade. Marília: Poiesis, Oficina Universitária; São Paulo: Cultura Acadêmica, 2010. p. 15-33. 
VALDEMARIN. Vera Teresa. Cultura escolar e conhecimento científico. In: SOUZA, Rosa Fátima; VALDEMARIN, Vera Tereza (Org.). A cultura escolar em debate: questões conceituais, metodológicas e desafios para a pesquisa. Campinas, SP: Autores Associados, 2005.

Data de recebimento: $18 / 10 / 2011$

Data de aceite: $21 / 11 / 2011$ 